\title{
Análisis de viabilidad de la banca ética en España a través de Triodos Bank. Comparativa económico-financiera con la banca tradicional ${ }^{1}$
}

\author{
Emilio Abad Segura² y Ma del Carmen Valls Martínez ${ }^{3}$
}

Recibido: 28 de agosto de 2017 / Aceptado: 9 de abril de 2018

Resumen. La Banca Ética es la respuesta a décadas de especulación financiera y a inversiones alejadas de un compromiso ético y cooperativo por parte de la banca tradicional. Constituye el instrumento necesario para gestionar el negocio bancario desde la transparencia, con códigos sociales y medioambientales, sin olvidar la rentabilidad económica para resistir y permanecer en un sistema financiero exigente. El presente trabajo tiene como objetivos, por un lado, estudiar el origen y las características de la banca ética, que aunque no es ajena a los momentos de contracción económica, su misión posibilita que sea una alternativa a la dependencia del sector bancario tradicional; y, por otro lado, examinar las condiciones e iniciativas que la entidad Triodos Bank realiza para posicionarse como banco líder con valores éticos y, a su vez, comparar sus resultados con los obtenidos por las principales entidades financieras de la banca convencional.

Palabras clave: Finanzas Éticas; Triodos Bank; Inversión Socialmente Responsable; Banca Social.

Claves Econlit: A13; G21; M21.

\section{[en] Analysis of viability of the ethics bank in Spain through Triodos Bank. Comparison economic-financial with traditional bank}

\begin{abstract}
Ethical Banking is the answer to decades of financial speculation and investments away from an ethical and cooperative commitment of traditional banking. It is the necessary instrument to manage the banking business from transparency with social and environmental codes, without forgetting the economic profitability to resist and remain in a demanding financial system. The purpose of this paper, on the one hand, is to study the origin and characteristics of ethical banking, which, although not unconnected with economic downturns, makes it an alternative to dependence on the traditional banking sector; and, on the other hand, to examine the conditions and initiatives that Triodos Bank performs to position itself as a leading bank with ethical values and, in turn, to compare its results with those obtained by the main financial entities of conventional banking.
\end{abstract}

Keywords: Ethical Finance; Triodos Bank; Socially Responsible Investment; Social Bank.

1 Este trabajo ha sido parcialmente financiado por el proyecto "La sostenibilidad del sistema nacional de salud: reformas, estrategias y propuestas" (DER2016-76053-R), Programa Estatal de I+D+I Orientada a los Retos de la Sociedad. Ministerio de Economía y Competitividad (España).

2 Universidad de Almería, España

Dirección de correo electrónico: eas297@ual.es

3 Universidad de Almería, España

Dirección de correo electrónico: mcvalls@ual.es 
Sumario. 1. Introducción. 2. Evolución de la banca ética en España. 3. Estudio del modelo de negocio de Triodos Bank. 4. Situación económico-financiera de Triodos Bank. 5. Conclusiones. 6. Referencias bibliográficas.

Cómo citar: Abad Segura, E. y Valls Martínez, M. (2018) Análisis de viabilidad de la banca ética en España a través de Triodos Bank. Comparativa económico-financiera con la banca tradicional. REVESCO. Revista de Estudios Cooperativos, Segundo Cuatrimestre, N ${ }^{\circ}$ 128, pp. 7-35. DOI: 10.5209/REVE.60205.

\section{Introducción}

La reputación del modelo bancario tradicional está seriamente cuestionada desde el inicio de la última crisis financiera mundial y, en consecuencia, se ha producido un interés por las finanzas éticas, en relación a los sectores que financian los ahorros depositados en las entidades bancarias (Karl, 2015; Alemán, 2015; Ruiz, Esteban y Gutiérrez, 2014; Soler y Melián, 2012; Pérez-Ruiz y Rodríguez, 2012; San José, Retolaza y Gutiérrez, 2011).

La banca social, promovida por todos los sectores de la sociedad, surge de la necesidad de integrar la ética con la actividad empresarial, priorizando el compromiso social a la rentabilidad económica. Su transparencia operativa motiva que este modelo de banca realice actividades justificadas éticamente de captación y de inversión de fondos. De este modo, el criterio ético afecta plenamente a la entidad y no sólo a la creación de determinados productos éticos o a la participación en criterios de responsabilidad social de la empresa (San José, Retolaza y Gutiérrez, 2011; Cabaleiro y Rodríguez, 2008; Retolaza y San Emeterio, 2003).

El enfoque social de los servicios financieros se remonta a la década de los setenta, que propició la aparición de diversos movimientos e instituciones que instaban a un sistema económico y financiero más solidario con el medioambiente y las personas. Existía un convencimiento generalizado de que el sistema financiero podría ser una herramienta para obtener mejoras sociales (Sanchís, 2016; Alejos, 2014). Es innegable que el desarrollo necesita ser sostenible, y para ello se debe poner un especial énfasis en favorecer y promocionar una cultura de desarrollo social y respeto con el medioambiente, para así obtener rendimientos económicos y de mejora social (Mishra, 2015; Dorasamy, 2013; De la Cruz, Sasia y Garibi, 2006).

En este sentido, la banca ética, compuesta por bancos y sociedades cooperativas de crédito, ejerce sus funciones de intermediario financiero dentro de la estructura y regulación del sistema financiero, cuya actividad principal es la de captar fondos de sus clientes para conceder créditos y realizar proyectos de inversión con carácter ético, dando de este modo sentido a las inversiones de los ahorradores sensibilizados con el destino de su capital (Sanchís y Pascual, 2017; Castro y Romero, 2011; Cabaleiro y Rodríguez, 2008). Los riesgos financieros asumidos por el sector financiero han repercutido en el resto de sectores, de modo que esta conducta prolongada ha contribuido a que la banca y, en general, el sector del crédito tomen de alguna forma conciencia del desgaste al que exponen a la sociedad y hayan comercializado de forma creciente productos de activo y pasivo éticos dirigidos a la confianza de los clientes comprometidos y el desarrollo de la 
banca social (Serrano, 2017; Paulet, Parnaudeau y Relano, 2015; Condosta, 2012; Toña, Sasia y Garibi, 2006).

El trasfondo y la naturaleza de este modelo adquieren sentido cuando se cuestiona el derecho al crédito en las sociedades capitalistas. Así, este modelo bancario ha irrumpido como una respuesta alternativa con un planteamiento más ético en la situación económica actual al poner en duda la intermediación financiera tradicional (Kousis, 2017; De la Cruz y Sasia, 2010; Knights, 2009). Asimismo, su actividad se dirige a limitar el crédito a iniciativas que no cumplan los criterios positivos y responsables que establecen, con objeto de frenar proyectos empresariales que tengan un efecto negativo para la sociedad. En ese orden, se puede calificar como una evolución de la intermediación financiera, reconociendo un valor social en el mecanismo de su función y plantear quién y por qué tiene derecho al crédito (Ochoa, 2013; Sasia, 2012).

La deteriorada imagen de las entidades tras la crisis financiera obliga a las compañías a elaborar estrategias de Responsabilidad Social Corporativa (RSC). En este contexto, se ha evaluado la percepción que los clientes tienen de las entidades bancarias y la transición que supone generar de nuevo confianza en el sector financiero (Ochoa, 2013; Rosero, Pinzón y Ramírez, 2013; Pérez-Ruiz y Rodríguez, 2012).

Si bien la actividad que realiza la banca convencional y la banca ética es afín, puesto que ofertan productos financieros análogos, ésta responde a criterios sociales y culturales muy diferentes. En efecto, el objetivo principal de la banca tradicional es el económico, es decir, trata de maximizar la rentabilidad y los beneficios con su actividad, independientemente, en general, del impacto que pudiera tener el proyecto que financia (Castro y Romero, 2011; San José y Retolaza, 2007; Toke, 2005). En consecuencia, para que una entidad pueda ser considerada como ética, además de ejercer y operar como una entidad convencional, se debe comportar como un servicio público comprometido con la aportación de servicios básicos a la sociedad, de modo que su gestión incluye tanto la responsabilidad interna, referida a la transparencia de su operatividad, como la externa, canalizando el ahorro hacia la inversión con fines éticos (Baraibar-Díez, Odriozola y Sánchez, 2017; Cornée, 2017; Narrillos, 2010). Al mismo tiempo, la banca con valores tiene la condición de herramienta política (Gassiot, 2013; De la Cruz y Sasia, 2010), estableciendo la unión entre el reclamado derecho al crédito y la intermediación financiera desde el ámbito de la solidaridad y en contraste con la especulación (Halamka y Teplý, 2017; Corneé, 2017).

Aunque la investigación en banca ética es escasa, está incrementándose en los últimos años y existe un reconocimiento por parte de la comunidad científica que muestra un interés en definir temas intrínsecos a este modelo bancario como son, entre otros, definir las características que permiten a una entidad pertenecer a este modelo de finanzas, o determinar la creación de valor que aportan con su actividad (Bosheim, 2012). Este déficit de investigación puede estar sustentado en la falta de regulación que delimite a este modelo de banca y; al no estar definidas estrictamente sus características y particularidades ni existir un registro, una entidad puede libremente decidir si se vincula a este movimiento.

Ahora bien, llegado a este punto se hace necesario reflexionar acerca de si en España, como sí ha sucedido en otros países europeos, este modelo bancario tiene 
opciones de, en primer lugar, reconocerse y, posteriormente, consolidarse como un referente en el negocio bancario. El caso más significativo es Triodos Bank que, tanto en España como a nivel europeo, ha venido incrementando sus cifras de negocio y beneficios desde su implantación (Chew, Tan y Hamid, 2016; Alejos, 2014; Retolaza y San Emeterio, 2003; Cowton y Thompson, 2001).

Para evaluar si la consolidación de la banca social es un hecho, se hace necesario el desarrollo de trabajos e investigaciones que estudien, por un lado, la cuota de mercado que presentan el conjunto de entidades financieras sostenibles en el sector del crédito y la inversión y, por otro, si la percepción e imagen que tienen los clientes, usuarios y la sociedad están en línea con la misión que define este modelo bancario. Además, sería positivo un análisis entre entidades financieras de ambos modelos, desde los puntos de vista de la solvencia y los riesgos asumidos, con objeto de cuantificar las diferencias o similitudes en sus actividades. Los resultados que se obtengan explicarán a efectos prácticos la importancia de su implantación a escala nacional e internacional y no que sólo sea una respuesta a las necesidades de crédito de pequeñas zonas vinculadas al subdesarrollo.

Es preciso señalar que, la banca social engloba a todas aquellas entidades del negocio bancario cuya gestión está guiada por los principios de transparencia, comunicación y participación y que tienen un impacto social luchando contra la pobreza y la exclusión o favoreciendo el desarrollo sostenido mediante la preservación del medio ambiente, todo ello respetando valores éticos (Soler y Melián, 2012). Así pues, podemos distinguir dentro de la banca social dos grandes categorías: por una parte, aquellos bancos dedicados a la reducción de la pobreza en el tercer mundo y, por otro lado, los denominados bancos éticos, que operan en los países desarrollados. En este sentido, considerando nuestro entorno, es usual hablar indistintamente de banca social y banca ética, si bien es cierto que el concepto de banca social es más amplio.

El presente trabajo tiene como objetivo principal examinar las características específicas de la banca ética, para así establecer las diferencias más significativas con el modelo tradicional. Para ello, estudiaremos la situación económicofinanciera de Triodos Bank y realizaremos un análisis comparativo con las dos principales entidades financieras españolas, Banco Santander y Banco Bilbao Vizcaya Argentaria (BBVA). La metodología utilizada ha consistido en el análisis comparativo a través de los informes anuales publicados por los bancos.

La estructura del trabajo es la siguiente: en la Sección 2 se han definido las singularidades de la banca ética y cómo ha evolucionado para destacarse como una alternativa al modelo especulativo; en la Sección 3 se estudia la entidad Triodos Bank, referente de la banca ética en Europa y España; en la Sección 4 se realizará un análisis de la actual situación económico-financiera de Triodos Bank, además de una comparativa con el modelo bancario convencional en España a través de un análisis de ratios; por último, en la Sección 5 se presentan las conclusiones obtenidas. 


\section{Evolución de la banca ética en España}

La inclusión de las finanzas éticas en la economía española está vinculada a la creciente preocupación por los temas sociales en las últimas décadas por un amplio sector de la sociedad. De hecho, la principal función de la banca solidaria es la de aportar soluciones financieras a los colectivos excluidos, por medio de distintos programas sociales que financian el trabajo y sus necesidades primarias (De la Orden y Sánchez, 2016; Vidal et al., 2006).

El sector bancario en España lleva décadas experimentando un cambio de rumbo, en la búsqueda de una alternativa que aglutine criterios económicos y sociales. Por un lado, se ha producido una concentración de las entidades financieras convencionales $\mathrm{y}$, por otro lado, se ha originado un crecimiento en el sector de la banca alternativa o social, tanto de las cooperativas de crédito como de los bancos éticos. Sin embargo, destaca el escaso marco normativo aplicable al sector de la banca ética en España, en oposición a lo que ocurre en los países del entorno (San José, Retolaza y Pruñonosae, 2014). En este sentido, el débil posicionamiento del concepto de banca ética llevó a la CNMV a aprobar y a la Asociación de Instituciones de Inversión Colectiva y Fondos de Pensiones (INVERCO) a elaborar la Circular, 8 de abril de 2014, sobre la aplicación de criterios medioambientales, sociales y de gobierno corporativo (ASG) en la política de inversión de las Instituciones de Inversión Colectiva (IIC), con objeto de proteger al inversor de una publicidad engañosa en los productos financieros con el calificativo "ético". Por otro lado, también habría que señalar la norma AENOR: UNE 165001:2012, que presenta los requisitos que deben cumplir los productos financieros de inversión para ser calificados como socialmente responsables.

En esencia, dentro de las finanzas éticas en España se distinguen instrumentos financieros tales como productos financieros éticos asociados a los mercados de valores, que incluyen los fondos de inversión éticos, los fondos de pensiones éticos y las acciones y bonos éticos, microcréditos, instrumentos crediticios y de ahorro éticos, y la propia banca ética (Gutiérrez, 2004).

Los clientes de esta banca alternativa pertenecen a colectivos con un alto compromiso social que necesitan conocer el destino de sus ahorros. Entre estos podemos encontrar a las entidades sociales que forman parte de los movimientos de Economía Alternativa y Solidaria (REAS), las organizaciones no gubernamentales para el desarrollo, las congregaciones religiosas y a los ciudadanos socialmente responsables (Toña, Sasia y Garibi, 2006).

Así, la banca social está demostrando que es una alternativa fiable y resistente a las tentaciones del sistema financiero que tanto ha deteriorado la imagen del sector bancario. Del mismo modo que ha sucedido desde el inicio de la crisis en entidades financieras tradicionales, en un grupo de instituciones éticas (Triodos Bank España, Fiare Banca Ética, Coop 57, Oikocredit España, etc.) el capital destinado a operaciones de préstamo fue superado en 2011 por el ahorro de los clientes bancarios (véase Figura 1). La tendencia ha sido creciente en estos ocho años, y destaca que en 2015 y 2016 el ahorro prácticamente duplica al capital concedido en préstamos. 
Figura. 1. Evolución ahorro y préstamo en el sector de las Finanzas Éticas en España, 20082016 (en miles de euros)

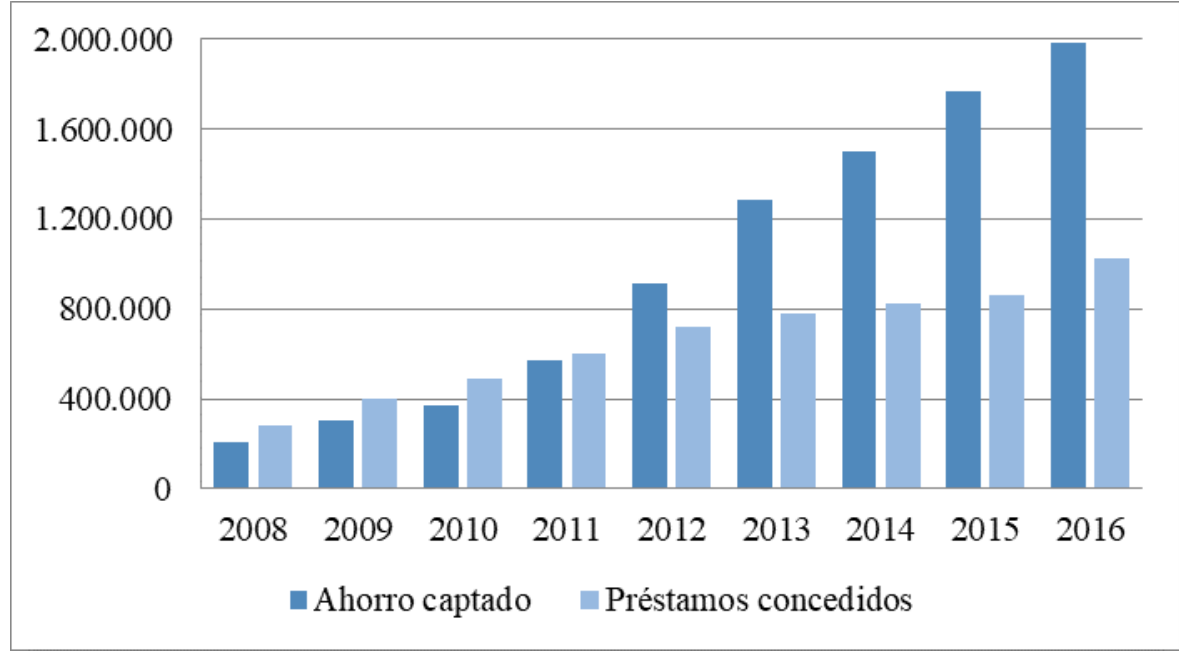

Fuente: Barómetro de las Finanzas Éticas y Solidarias, 2016

El comportamiento responsable y la credibilidad que están acumulando las entidades éticas, ayudan a cambiar la mentalidad de una sociedad que pretende planificar los riesgos y ser partícipes de las reglas de un sistema que ha actuado contra la calidad de vida y la dignidad humana. En este sentido, el impacto que tiene la banca ética también se puede medir en el incremento del 48,3\% que está teniendo en el número de clientes y usuarios desde 2013 a 2016, donde la morosidad, es decir, el cociente entre el valor de los créditos dudosos y el valor de la cartera de créditos totales se sitúa en el 6,1\%, y las aportaciones de capital en 171 millones de euros en 2016 (véase Tabla 1).

Tabla. 1. Evolución No de Clientes/Usuarios, Tasa de morosidad y Capital, 2013-2016

\begin{tabular}{llll}
\hline Año & Clientes/Usuarios & Tasa Morosidad $(\%)$ & Capital $(€)$ \\
\hline 2013 & 159.408 & 4,18 & - \\
2014 & 187.383 & 8,17 & 129.687 .542 \\
2015 & 214.922 & 7,04 & 144.814 .168 \\
2016 & 236.341 & 6,12 & 170.790 .061 \\
\hline
\end{tabular}

Fuente: Barómetro de las Finanzas Éticas y Solidarias, 2016

El movimiento de la banca social busca asociarse para generar vínculos entre las entidades y formar una alianza más visible en el sector de las finanzas mundiales. Así, surgen instituciones y redes en este sentido como: The Institue for Social Banking (ISB), la Federación Europea de Bancos Éticos y Alternativos (FEBEA), la International Association of Investors in the Social Economy (INAISE) y la Global Alliance for Banking on values (GABV). Cabe señalar que la GABV es una 
red internacional que tiene por finalidad ampliar el impacto de la banca ética y sostenible a nivel global y que en junio de 2017 estaba formada por 7 socios estratégicos y 43 bancos sostenibles independientes, entre los que se encuentran diez europeos: Alternative Bank Switzerland y Freie Gemeinschaftsbank Genossenschaft (Suiza), Banca Popolare Ética (Italia), Crédit Coopératif (Francia), Culture Bank (Noruega), Ekobanken (Suecia), GLS Bank (Alemania), Magnet Bank (Hungría), Merkur Resource Bank (Dinamarca) y Triodos Bank (Países Bajos) (GABV, 2017). Destaca esta última entidad como uno de los miembros fundadores de la GABV y referente actual en la banca que promueve la renovación social desde el sistema financiero.

\section{Estudio del modelo de negocio de Triodos Bank}

\subsection{Origen e implantación}

El periplo de Triodos Bank comenzó a gestarse en 1968 cuando un grupo de profesionales del Derecho y la Economía decidieron gestionar de forma sostenible su capital. Así, en 1971 se crea la Fundación Triodos, dedicada a captar fondos de donantes privados con objeto de invertirlos en actividades con fines sociales, medioambientales y culturales. Posteriormente, en 1980, la fundación da paso a la entidad financiera de carácter social y medioambiental Triodos Bank N.V. en Zeist, Países Bajos, dando lugar al referente en Europa en banca ética y sostenible. Posteriormente, el desarrollo de su actividad bancaria les ha permitido crear una serie de fondos verdes y de microcréditos, además de una rápida expansión, constituyéndose como la entidad respetada en el sector ético y financiero, ajena a la especulación.

Así, el Grupo Triodos engloba las actividades bancarias de Triodos Bank y la actividad de inversión de Triodos Investment Management y de Banca Privada, con presencia en los Países Bajos, Bélgica, Reino Unido, España, Alemania, y cuenta con una agencia en Francia.

En particular, Triodos Bank es una sociedad anónima que se rige por las leyes holandesas y su actividad es la de financiar empresas, instituciones y proyectos con valor social, medioambiental y cultural, a partir de los ahorros e inversiones que apuestan por conseguir una sociedad sostenible. Por otro lado, los usuarios cada vez más exigen que la RSC en las entidades financieras no sea sólo un concepto académico, sino que se convierta en una herramienta relacionada directamente con las iniciativas e inversiones sociales, culturales y medioambientales (Pérez-Ruiz y Rodríguez, 2012).

En la actualidad, los ahorros captados a sus clientes les permiten financiar proyectos sostenibles, ofreciendo un modelo bancario basado en la transparencia. Además de su presencia en varios países europeos, desarrolla una intensa actividad en diversos países de América Latina, Asia y África con la aplicación de sus fondos de inversión y microcréditos.

En 2016, el patrimonio gestionado por el Grupo Triodos Bank era de 13.454 millones de euros, con un incremento del 9,40\% respecto al ejercicio anterior. En cuanto a los sectores sostenibles que financia, por la acumulación de experiencia y 
conocimientos adquiridos y advirtiendo que el objetivo es destinar al crédito entre el $65 \%$ y el $75 \%$ de los fondos propios, destacan: medioambiente (38\%), social (24\%), cultura y ocio (14\%), y préstamos concedidos a particulares, ayuntamientos e hipotecas sostenibles residenciales (24\%).

$\mathrm{Su}$ origen en España data de 1998 con la creación de la sociedad mercantil Proyecto Trust, que tenía por finalidad actuar como consultora e invertir en proyectos de los sectores social, cultural y medioambiental. Posteriormente, se convierte en Triodos Investments, agente financiero de Triodos Bank en España; y, finalmente, en septiembre de 2004 se convierte en Triodos Bank España, con capacidad plena para operar como entidad financiera con el número de registro 1.491 en el Banco de España. Actualmente, en 2017, dispone de oficinas en prácticamente todas las comunidades autónomas, excepto en Cantabria y La Rioja, y en las ciudades autónomas de Melilla y Ceuta.

Destaca que es un banco que no cotiza en Bolsa con el objeto de, como la misma entidad señala, no estar sometido a los vaivenes de precios que se producen en el mercado de capitales. De hecho, las acciones de la entidad están gestionadas por la Fundación para la Administración de las Acciones de Triodos Bank (SAAT).

Según el barómetro de Finanzas Éticas y Solidarias de 2016, Triodos Bank España es la entidad financiera con características más similares a la banca convencional, pero con el valor añadido que supone la inversión en iniciativas o proyectos culturales, sociales y medioambientales que tienen un impacto positivo en la sociedad.

\subsection{Proyectos de inversión financiados por Triodos Bank}

Para llevar a cabo la política de inversión responsable, Triodos Bank aplica una serie de criterios positivos de financiación de sostenibilidad e impacto social y medioambiental, con los que evalúa la concesión de préstamos (véase Tabla 2), permitiendo a sus grupos de interés tener constancia de la contribución que realizan a la sociedad y ser partícipes del éxito de las iniciativas llevadas a cabo por los distintos agentes.

Tabla. 2. Criterios de financiación de Triodos Bank

\section{Criterios para la concesión de préstamos}

1. Identificación de sectores sostenibles, con objeto de desarrollar y consolidar empresas y proyectos innovadores. Establece criterios positivos de financiación.

2. Selección de iniciativas concretas que sean beneficiosas para la sociedad, primando aquellas que aporten un mayor valor añadido de tipo social, medioambiental o cultural, así como financiero y comercial.

3. Tener la certeza de que cada proyecto seleccionado sea contrastado con los criterios de exclusión del banco.

4. Financia proyectos, actividades o activos identificados dentro de cada empresa u organización. Por ello, en su política de financiación se centra en las PyMES, así como en entidades sin ánimo de lucro, para tener una relación cercana y directa con las personas que trabajan en ellas y así tener constancia de la consecución del proyecto. 
5. Supervisar el uso del capital prestado.

Fuente: Triodos Bank

En este sentido, Triodos analiza cada una de las propuestas de financiación individualmente, de modo que no financia determinados proyectos e iniciativas que cuestionen el desarrollo sostenible de la sociedad y que participen en más de un 5\% de su actividad en determinados sectores:

- Productos y servicios no sostenibles (industria peletera, apuestas, energía nuclear, sustancias peligrosas para el medioambiente, pornografía, tabaco e industria armamentística).

- Procesos de trabajo no sostenibles (sistemas de producción de agricultura intensiva, corrupción, regímenes dictatoriales, experimentación con animales, ingeniería genética, infracción de legislación ambiental, laboral, códigos de conducta o convenciones).

- $\quad$ Otros sectores y actividades que no respeten el espíritu de la entidad.

Así, la política de financiación de Triodos Bank se centra en sectores comprometidos con el desarrollo social y sostenible, fundamentalmente: naturaleza y medioambiente, e iniciativas sociales y culturales (véase Tabla 3).

Tabla. 3. Sectores financiados por Triodos Bank*

\begin{tabular}{ll}
\hline Sector & Política de financiación \\
\hline Naturaleza y & El cambio climático es uno de los mayores problemas a los \\
medioambiente & $\begin{array}{c}\text { que se enfrenta el planeta en su conjunto. Para combatirlo, } \\
\text { apuesta por financiar: } \\
\text { Proyectos de energía renovables e iniciativas de } \\
\text { tecnología medioambiental, potenciando modelos } \\
\text { energéticos sostenibles y dando importancia al ahorro } \\
\text { energético. } \\
\text { Edificación sostenible. } \\
\text { Empresas del sector de la agricultura ecológica o } \\
\text { biodinámica. } \\
\text { Proyectos de conservación de la biodiversidad, } \\
\text { facilitando su gestión y ofreciéndoles condiciones } \\
\text { competitivas y servicios de calidad. } \\
\text { Tiene un compromiso real con los colectivos más débiles y } \\
\text { con necesidades especiales; por ello, financian a: } \\
\text { Empresas y organizaciones sin ánimo de lucro que } \\
\text { atienden a discapacitados, ancianos, niños, enfermos, } \\
\text { problemas de adicción, personas con riesgos de } \\
\text { exclusión social, es decir, que favorezcan la integración } \\
\text { social, la salud y la atención social. } \\
\text { La cooperación al desarrollo y el comercio justo, es } \\
\text { decir, que respeten el medioambiente y garanticen los } \\
\text { derechos de las personas. }\end{array}$ \\
\hline
\end{tabular}


Cultura

Es una herramienta para el desarrollo de economías locales y la diversidad cultural fomentando el ocio y el turismo sostenible. Financia:

- Iniciativas y empresas dedicadas a la industria cultural.

- Educación e investigación: escuelas y centros educativos donde priman valores como la libertad de pensamiento, la tolerancia o la dignidad, y que fomentan la creatividad y el desarrollo personal.

- Turismo y actividades de ocio sostenibles.

(*) Además financia a particulares y Ayuntamientos que cumplan con los criterios positivos de financiación de Triodos Bank.

Fuente: Triodos Bank.

En la Figura 2 se muestra la aportación que ha realizado Triodos Bank en 2016 en cada uno de los ámbitos que cuentan con valor social añadido; se observa un incremento de entre un $6 \%$ y un $12 \%$ de las inversiones del Grupo, donde destaca el notable aumento a particulares y a Ayuntamientos. En el caso de las operaciones de Triodos en España no sucede lo mismo en todos los sectores; por ejemplo, en medioambiente se han reducido a favor de otros sectores más desfavorecidos, como la vivienda social y la educación. Como ocurre con el resto de las oficinas del grupo Triodos, se ha producido un gran aumento en los créditos a particulares, lo que demuestra que la banca ética está llegando a un mayor número de usuarios y generando un efecto positivo en la sociedad, ya que la banca ética aporta soluciones financieras a colectivos excluidos de la financiación en la banca tradicional. 
Figura. 2. Inversión por sectores (Grupo Triodos Bank y Triodos Bank España), 2016.

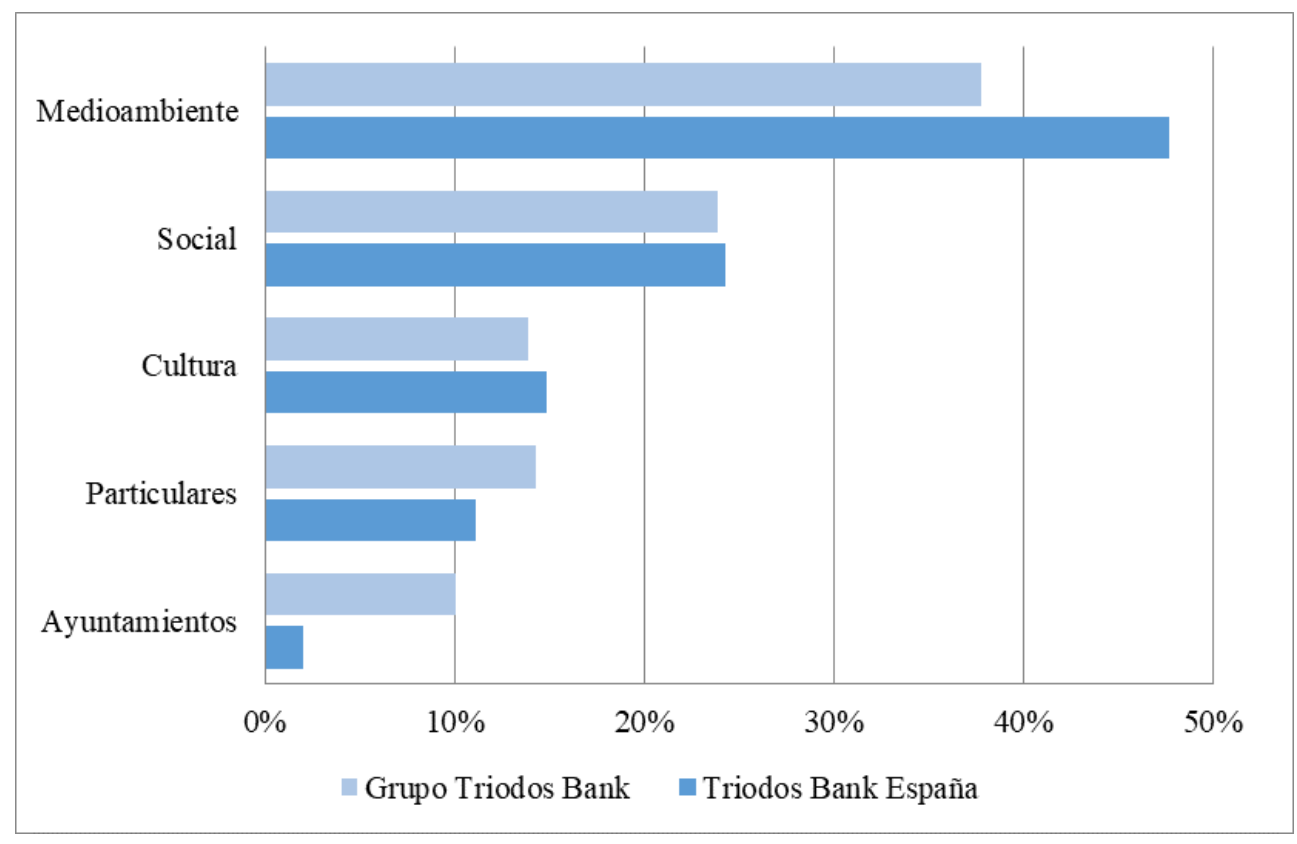

Fuente: Triodos Bank. Informe Anual 2016

Por último, respecto a la participación de España en el conjunto de inversiones de Triodos, señalar que el $17 \%$ de los préstamos concedidos se realizan en la sucursal española, indicando que los créditos concedidos por Triodos responden a iniciativas sostenibles que ayudan a mejorar el bienestar de los ciudadanos en su conjunto.

\subsection{Productos y servicios bancarios ofrecidos por Triodos Bank}

Triodos, al igual que las entidades de la banca tradicional, dispone de una amplia gama de productos y servicios financieros con los que cubre las necesidades de sus clientes, teniendo en cuenta que la actividad de la banca social tiene una serie de peculiaridades que la distinguen (carácter ético y responsable), así como el tipo de rentabilidad que se obtiene, que no sólo es económica, sino también social y medioambiental.

\subsubsection{Productos de Pasivo}

En relación con los recursos o pasivo, Triodos capta depósitos y ahorros de sus clientes, de modo que a través de las cuentas éstos realizan aportaciones que, en su conjunto, promueven un cambio positivo y sostenible en la sociedad (véase Tabla 4). Con estas donaciones se apoyan proyectos e instituciones que promueven el cumplimiento de los derechos humanos, la atención social, la cooperación al desarrollo, la ayuda humanitaria, la conservación de la naturaleza o la cultura. 
Tabla. 4. Cuentas para particulares, empresas y organizaciones

\begin{tabular}{|c|c|c|c|c|c|}
\hline Cliente & Cuenta & Características & T.A.E. & $\begin{array}{c}\text { Ahorro } \\
\text { periódico }\end{array}$ & $\begin{array}{l}\text { Donación } \\
\text { intereses }\end{array}$ \\
\hline \multirow{4}{*}{ Particulares } & Triodos & Sin comisiones & $0,05 \%^{1}$ & Sí & $\begin{array}{l}\text { Parte o } \\
\text { totalidad a } \\
\text { ONG }\end{array}$ \\
\hline & Infantil Triodos & $\begin{array}{l}\text {. Para el futuro } \\
\text { sostenible de los } \\
\text { niños }\end{array}$ & $0,05 \%^{1}$ & Sí & $\begin{array}{l}\text { Parte o } \\
\text { totalidad a } \\
\text { ONG }\end{array}$ \\
\hline & Vivienda Triodos & $\begin{array}{l}\text { Compra de } \\
\text { vivienda }\end{array}$ & $0,05 \%^{1}$ & Sí & $\begin{array}{l}\text { Parte o } \\
\text { totalidad a } \\
\text { ONG }\end{array}$ \\
\hline & Corriente Triodos & $\begin{array}{l}\text { Nómina y } \\
\text { recibos } \\
\text { domiciliados }\end{array}$ & $0,00 \%^{2}$ & Sí & No \\
\hline \multirow{4}{*}{$\begin{array}{l}\text { Empresas y } \\
\text { Organizaciones }\end{array}$} & Corporativa Triodos & Operativa diaria & $-0,36 \%^{3}$ & No & No \\
\hline & Triodos Empresa & $\begin{array}{l}\text { Cuenta de } \\
\text { ahorro } \\
\text {. Refuerza la RSC }\end{array}$ & $0,05 \%^{1}$ & Sí & $\begin{array}{l}\text { Parte o } \\
\text { totalidad a } \\
\text { ONG }\end{array}$ \\
\hline & Negocio Triodos & $\begin{array}{l}\text { de la empresa } \\
\text { Sin comisiones } \\
.0 € \text { por ingreso } \\
\text { de cheques } \\
.0 € \text { por el pago a }\end{array}$ & $4,84 \%^{4}$ & No & No \\
\hline & & $\begin{array}{l}\text { proveedores y } \\
\text { nóminas }\end{array}$ & & & \\
\hline
\end{tabular}

1 Liquidación y abono mensual de intereses.

$0,05 \%$ interés nominal anual para saldo hasta 5.000€. El saldo superior a 5.000€ no tiene remuneración.

2 Comisión por mantenimiento de cuenta corriente $1 € /$ mes (liquidación trimestral)

Comisión por emisión y mantenimiento de tarjeta de débito: $24 €$

Comisión por emisión y mantenimiento de tarjeta de crédito $34 €$.

TAE:

Si se cumplen todas las condiciones de vinculación revisables trimestralmente: $0,00 \%$ para cuenta no remunerada y en el supuesto en el que se mantenga de forma constante durante 1 año un saldo diario de $2.500 €$.

No se cumplen las condiciones de vinculación, para los mismos supuestos la TAE es de $-0,48 \%$.

3 TAE $0,36 \%$ para el supuesto de que se mantenga de forma constante durante 1 año un saldo diario de 10.000 $€$.

4 TAE calculada para una línea de crédito de cualquier importe, a un plazo de 1 año y con el importe totalmente dispuesto $(4,75 \% \mathrm{TIN})$.

Fuente: Triodos Bank

Otro producto cuyo incremento ha sido notable en la actividad de Triodos en el último año han sido los depósitos (véase Tabla 5). La gama de depósitos ofertada 
no es muy amplia y la rentabilidad ofrecida es baja, pero los ahorradores que contratan estos productos lo hacen por pura convicción, sabiendo que su dinero va a aportar un beneficio social positivo, teniendo disponible en todo momento la información referente al uso de esos depósitos, los proyectos que están financiando y la rentabilidad económica y social que se está obteniendo. Este depósito ofrece la posibilidad al ahorrador de donar parte o la totalidad de los intereses producidos a una organización de los sectores social, cultural y medioambiental.

Tabla. 5. Depósito para particulares, empresas y organizaciones

\begin{tabular}{lllll}
\hline Depósito & Plazo & Abono intereses & T.A.E. $^{1}$ & Donación intereses $^{\mathbf{2}}$ \\
\hline Triodos 12 & $\begin{array}{l}12 \text { meses } \\
\text { a partir de 3.000€ }\end{array}$ & Al vencimiento & $0,05 \%$ & $\begin{array}{l}\text { Parte o totalidad a una } \\
\text { ONG }\end{array}$ \\
\hline
\end{tabular}

\footnotetext{
${ }^{1}$ Fijo hasta vencimiento.

Saldo < 1M€: Interés nominal anual 0,05\%.

Saldo > 1 M€: no tiene remuneración.

${ }^{2}$ Podrá desgravarse en la declaración de la renta.
}

Fuente: Triodos Bank

Como entidad bancaria referente en el uso de las nuevas tecnologías, Triodos ofrece a sus clientes tarjetas de débito y crédito, promoviendo con ellas el uso responsable y el comercio seguro (véase Tabla 6), de modo que sus usuarios pueden utilizarlas en cualquier cajero de las entidades con las que tiene acuerdos, sin comisiones.

Tabla. 6. Tarjetas bancarias para particulares, empresas y organizaciones

\begin{tabular}{|c|c|c|c|}
\hline Tarjeta & Características & Condiciones & Ventajas \\
\hline Débito Triodos & $\begin{array}{l}\text { Consumo } \\
\text { responsable }\end{array}$ & $\begin{array}{l}\text { Tener abierta una Cuenta } \\
\text { Corriente Triodos } \\
\text { Cuota de emisión y } \\
\text { mantenimiento (anual): } 24 € \\
\text { Comisión por duplicado: } 8 € \\
\text { Retirar efectivo sin comisiones } \\
\text { en cajeros Triodos } \\
\text {. Retirar efectivo a débito sin } \\
\text { costes } 2 \text { veces al mes en los } \\
\text { cajeros de Bankia, Bankinter e } \\
\text { ING. A partir de la } 3^{\text {a } e x t r a c c i o ́ n ~} \\
\text { al mes, se aplica la comisión que } \\
\text { la entidad cobre por el servicio }\end{array}$ & $\begin{array}{l}\text {. Fabricada en PVC } 100 \% \\
\text { biodegradable } \\
\text { Aviso SMS de cargo en } \\
\text { cuenta } \\
\text { Ingreso de efectivo en } \\
\text { cajeros Triodos }\end{array}$ \\
\hline
\end{tabular}




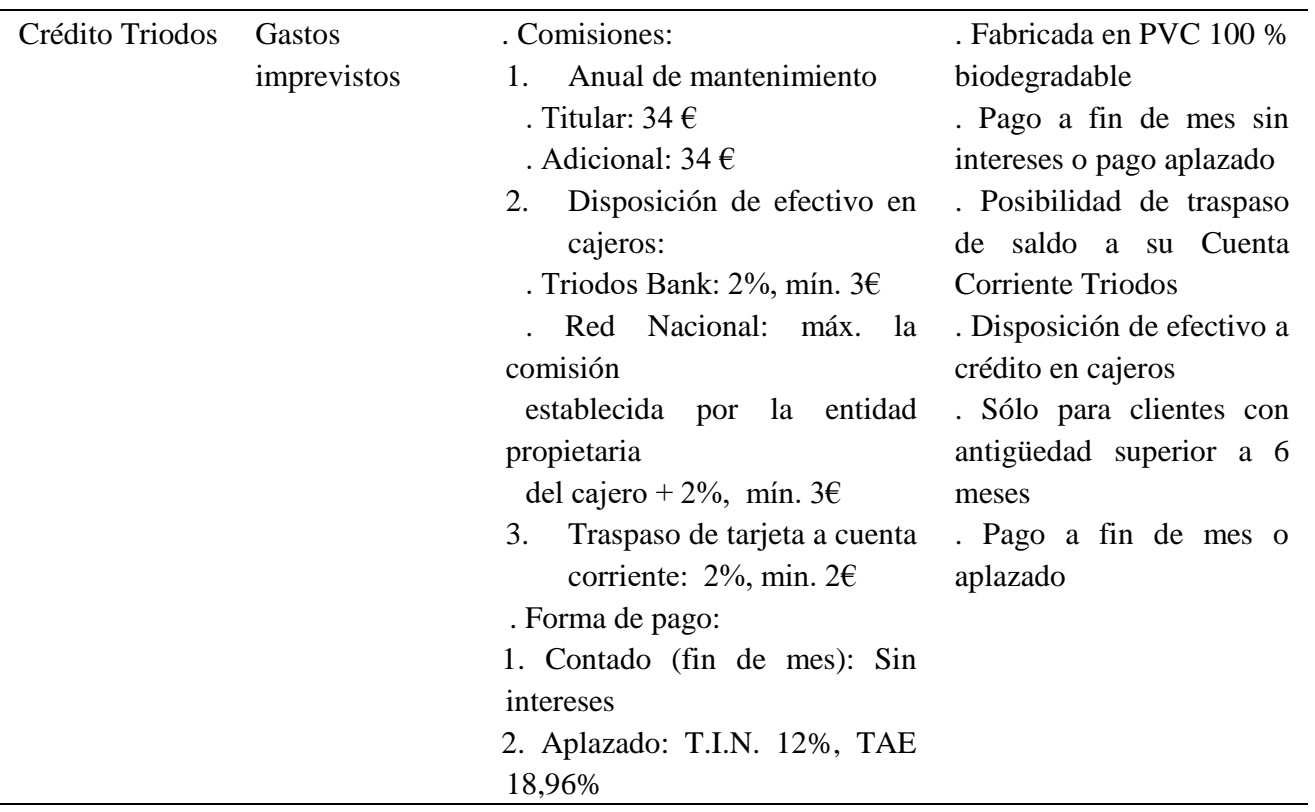

Fuente: Triodos Bank

Por último, en relación con los productos de pasivo relacionados con la inversión, ofrece la posibilidad de hacer partícipes en el desarrollo de la banca ética a sus clientes, pudiendo adquirir CDA, cuyo precio por certificado es de 82 euros (véase Tabla 7).

Tabla. 7. Características Certificados de Depósitos para Acciones (CDA)

\begin{tabular}{lcccc}
\hline \multicolumn{1}{c}{$\begin{array}{c}\text { Producto de } \\
\text { Inversión }\end{array}$} & Precio & $\begin{array}{c}\text { Comisión de } \\
\text { transacción }\end{array}$ & Rentabilidad $^{2}$ & Retorno \\
\hline & & & & $2016: 5,0 \%$ \\
Certificados de & & & 3 años: $4,6 \%$ & $2015: 5,1 \%$ \\
Depósito para & $82 €$ & $0,50 \%$ & 5 años: $4,4 \%$ & $2014: 5,3 \%$ \\
Acciones (CDA) & & & 10 años: $4,4 \%$ & $2013: 4,0 \%$ \\
& & & & $2012: 4,0 \%$ \\
\hline
\end{tabular}

${ }^{1}$ El precio de los CDA de Triodos Bank se determina por el valor neto de los activos del banco, divido por el número de certificados emitidos.

${ }^{2}$ A 31-05-2017.

Fuente: Triodos Bank 


\subsubsection{Productos de Activo}

Cada producto tiene sus propias condiciones, debido a que Triodos Bank las establece en función del tipo de proyecto y cliente que lo solicita. Llevan un seguimiento constante posterior a la concesión. Destaca la EcoHipoteca para la construcción de viviendas sostenibles y eficientes, cuya eficiencia se remunera con una reducción del tipo de interés (véase Tabla 8).

Tabla. 8. Características de la Hipoteca Triodos

\begin{tabular}{|c|c|c|c|c|c|}
\hline $\begin{array}{c}\text { Criterios de } \\
\text { sostenibilidad }\end{array}$ & $\begin{array}{c}\text { TAE } \\
\text { variable }\end{array}$ & Plazo & Importe & Comisión & $\begin{array}{c}\text { Vinculaciones } \\
\text { asociadas }\end{array}$ \\
\hline $\begin{array}{l}\text { Eficiencia } \\
\text { Energética } \\
\text { (más ahorro y } \\
\text { reducción de } \\
\text { las emisiones } \\
\text { de } \mathrm{CO}_{2} \text { ) }\end{array}$ & $\begin{array}{l}\text {. Vinculado a } \\
\text { la } \\
\text { certificación } \\
\text { energética de } \\
\text { la vivienda }\end{array}$ & $\begin{array}{l}\text {. Hasta un } \\
\text { máx. de } 30 \\
\text { años } \\
\text {. Edad límite } \\
\text { para rar el } \\
\text { establecimient } \\
\text { o del plazo: } \\
70 \text { años }\end{array}$ & $\begin{array}{l}\text { Hasta un } \\
80 \% \text { de } \\
\text { tasación o } \\
\text { del valor } \\
\text { de } \\
\text { comprave } \\
\text { nta }\end{array}$ & $\begin{array}{l}\text { Apertura: } 0 \% \\
\text {. Novación y } \\
\text { subrogación: } \\
0,5 \% \\
\text {. Desistimiento } \\
\text { total o parcial: } \\
0 \% \\
\text { de Reclamación } \\
\text { de impago: } 30 €\end{array}$ & $\begin{array}{l}\text { Domiciliación } \\
\text { de nómina } \\
\text { Tres recibos } \\
\text { domésticos } \\
\text { Seguros de } \\
\text { vida y contra } \\
\text { incendios } \\
\text { Tarjetas de } \\
\text { crédito } \\
\text { débito }\end{array}$ \\
\hline
\end{tabular}

Fuente: Triodos Bank

\section{Situación económico-financiera de Triodos Bank}

\subsection{Análisis de los Estados Financieros}

El estado económico-financiero de la entidad se presenta en cada ejercicio económico en el Informe Anual en su web corporativa. Igualmente, cumpliendo con el principio de fomentar la transparencia de su actividad bancaria, publica información no financiera.

La Tabla 9 muestra la evolución de las masas patrimoniales del activo, pasivo y fondos propios en el balance consolidado de los últimos tres períodos del Grupo Triodos. Así, las cuentas anuales consolidadas incluyen los datos financieros de Triodos Bank, las sociedades del grupo y otras compañías gestionadas por Triodos, es decir, participaciones en empresas en las que tiene un interés directo o indirecto de control de acuerdo a los derechos de voto. En la confección de estas cuentas anuales se eliminan las deudas, las cantidades por recibir y las transacciones entre empresas del grupo. Por otro lado, los activos y pasivos se consideran según su valor histórico, y en las deudas pendientes de cobro se tiene en cuenta una provisión por dudoso cobro. 
Tabla. 9. Balance consolidado, 2016-2014 (en miles de euros)

\begin{tabular}{|c|c|c|c|c|c|}
\hline & \multirow[b]{2}{*}{2016} & \multirow[b]{2}{*}{2015} & \multirow[b]{2}{*}{2014} & \multicolumn{2}{|c|}{ Variación (\%) } \\
\hline & & & & $16-15$ & 15-14 \\
\hline ACTIVO & 9.081.238 & 8.211.151 & 7.152 .404 & $10,60 \%$ & $14,80 \%$ \\
\hline Caja y bancos centrales & 732.219 & 285.819 & 175.225 & $156,18 \%$ & $63,12 \%$ \\
\hline Valores del Estado & 178.902 & 213.233 & 208.782 & $-16,10 \%$ & $2,13 \%$ \\
\hline Bancos & 467.529 & 545.152 & 575.743 & $-14,24 \%$ & $-5,31 \%$ \\
\hline Inversión crediticia & 5.708 .338 & 5.215 .692 & 4.266 .324 & $9,45 \%$ & $22,25 \%$ \\
\hline $\begin{array}{l}\text { Otros } \quad \text { valores } \\
\text { representativos de deuda }\end{array}$ & 1.718 .786 & 1.689 .968 & 1.710 .625 & $1,71 \%$ & $-1,21 \%$ \\
\hline Acciones & 20 & 65 & 4 & $-69,23 \%$ & $1.525,00 \%$ \\
\hline Participaciones en empresas & 16.411 & 13.803 & 8.720 & $18,89 \%$ & $58,29 \%$ \\
\hline Inmovilizado inmaterial & 25.159 & 18.589 & 13.364 & $35,34 \%$ & $39,10 \%$ \\
\hline $\begin{array}{l}\text { Bienes inmuebles y otros } \\
\text { activos fijos materiales }\end{array}$ & 56.725 & 58.392 & 39.821 & $-2,85 \%$ & $46,64 \%$ \\
\hline Otros activos & 24.800 & 18.154 & 13.215 & $36,61 \%$ & $37,37 \%$ \\
\hline Cuentas de periodificación & 152.349 & 152.284 & 140.581 & $0,04 \%$ & $8,32 \%$ \\
\hline $\begin{array}{l}\text { FONDOS PROPIOS } \quad+ \\
\text { PASIVO }\end{array}$ & 9.081.238 & 8.211 .151 & 7.152 .404 & $10,60 \%$ & $14,80 \%$ \\
\hline Fondos propios & 903.859 & 780.517 & 726.875 & $15,80 \%$ & $7,38 \%$ \\
\hline Capital & 554.415 & 484.329 & - & $14,47 \%$ & - \\
\hline $\begin{array}{l}\text { Reserva de prima de } \\
\text { emisión de acciones }\end{array}$ & 151.157 & 123.935 & - & $21,96 \%$ & - \\
\hline Reserva de revalorización & 689 & 503 & - & $36,98 \%$ & - \\
\hline Reserva estatutaria & 18.540 & 11.286 & - & $64,27 \%$ & - \\
\hline Otras reservas & 149.734 & 119.737 & - & $25,05 \%$ & - \\
\hline Resultado del ejercicio & 29.324 & 40.727 & - & $-28,00 \%$ & - \\
\hline Deuda subordinada & - & 5.250 & 5.250 & $100,00 \%$ & $0,00 \%$ \\
\hline Pasivo & 8.177.379 & 7.425.384 & 6.425 .529 & $10,13 \%$ & $15,56 \%$ \\
\hline Bancos & 31.582 & 39.798 & 54.627 & $-20,64 \%$ & $-27,15 \%$ \\
\hline Depósitos de clientes & 8.024 .620 & 7.282 .564 & 6.288 .828 & $10,19 \%$ & $15,80 \%$ \\
\hline Otras deudas & 16.822 & 20.744 & 1.208 & $-18,91 \%$ & $1.617,22 \%$ \\
\hline Cuentas de periodificación & 101.002 & 78.840 & 79.489 & $28,11 \%$ & $-0,82 \%$ \\
\hline Provisiones & 3.353 & 3.438 & 1.377 & $-2,47 \%$ & $149,67 \%$ \\
\hline
\end{tabular}

Fuente: Triodos Bank. Informes Anuales, 2016-2014 
El total de activos gestionados se incrementó desde 2014 en un $27 \%$, llegando hasta los 9.081 millones de euros, debido al constante crecimiento de los fondos depositados en el banco y a las ampliaciones de capital.

Dentro del activo destaca la Inversión Crediticia, que incluye el total de préstamos concedidos a los sectores sostenibles que financia, así como a Ayuntamientos y particulares. Asimismo, la Tabla 10 muestra los créditos de Triodos Bank, que se refiere a los préstamos clasificados por plazo remanente menos la provisión por deudores de dudoso cobro que realiza. Los préstamos se han incrementado en un $33,8 \%$ en este período, lo que demuestra la consolidada implantación de la entidad en los países europeos donde opera. En este sentido, el mayor volumen de la inversión crediticia se concede a largo plazo, lógico si se tiene en cuenta la misión y objetivos de la entidad, que busca tanto la rentabilidad económica como social. Por otro lado, también se han incrementado los recursos prestados de 1 a 3 meses, debido al fomento de los microcréditos para la puesta en marcha de proyectos a pequeña escala.

Tabla. 10. Inversión crediticia, 2016-2014 (en miles de euros)

\begin{tabular}{lrrr}
\hline & 2016 & 2015 & \multicolumn{1}{c}{2014} \\
\hline Créditos & & & \\
\hline A la vista & 192.884 & 218.517 & 257.525 \\
1 a 3 meses & 631.471 & 730.377 & 337.852 \\
3 meses a 1 año & 429.912 & 359.261 & 283.496 \\
1 a 5 años & 1.526 .954 & 1.202 .835 & 1.038 .412 \\
Más de 5 años & 2.984 .167 & 2.772 .753 & 2.416 .753 \\
Total Créditos & $\mathbf{5 . 7 6 5 . 3 8 8}$ & $\mathbf{5 . 2 8 3 . 7 4 3}$ & $\mathbf{4 . 3 3 4 . 0 3 8}$ \\
Provisión por deudores de dudoso cobro & -57.050 & -68.051 & -67.714 \\
\hline Total & $\mathbf{5 . 7 0 8 . 3 3 8}$ & $\mathbf{5 . 2 1 5 . 6 9 2}$ & $\mathbf{4 . 2 6 6 . 3 2 4}$ \\
\hline
\end{tabular}

Fuente: Triodos Bank. Informes Anuales, 2016-2014

En el activo también destaca la estabilidad de la cuantía en la "deuda y otros valores representativos de deuda", que incluye los Bonos del Estado de los Países Bajos, Bélgica, España y Reino Unido. Por otro lado, las acciones, con escasa participación en el total del Activo, corresponden a la participación en el sistema de pagos del banco en Society for Worldwide Interbank Financial Telecommunication (SWIFT, SCRL) y en el fondo Triodos Multi Impact Fund. El inmovilizado material se tasa al menos una vez cada cinco años; la última se realizó en noviembre de 2013. El incremento del valor en balance de las cuentas de periodificación (incluye: prima sobre inversiones en valores de renta fija, intereses devengados aún no facturados, impuestos diferidos, derivados y otras cuentas de periodificación) es debido a pérdidas fiscales incurridas por la sucursal alemana por un importe de 7,3 millones de euros (2015: 6,9 millones de euros), que se esperan recuperar íntegramente a través de beneficios futuros. 
La mayor parte del activo de Triodos está formado por activos menos líquidos a corto plazo, que se financia casi en su totalidad con los depósitos de clientes a corto plazo. Esto podría conllevar problemas de solvencia a muchas entidades, pero para Triodos no lo es, puesto que este banco lo que intenta es mantener un equilibrio adecuado entre préstamos y depósitos. Para ello, intenta cumplir su objetivo de concesión de préstamos a empresas sostenibles, utilizando los depósitos de los ahorradores en lugar de pedir prestado a otros bancos y estar sometidos a sus condiciones. A lo anterior hay que sumarle que Triodos mantiene un fuerte nivel de capitalización, consolidando así su solvencia a largo plazo. También es sometido de manera periódica a evaluaciones de riesgos, planteando distintos escenarios de estrés con los que mide su solvencia, liquidez y rentabilidad del capital.

En cuanto al pasivo, se observa un aumento de los depósitos de clientes en un $27,6 \%$ desde 2014. Triodos tiene una reputación consolidada a nivel europeo que está incrementando su actividad de forma notable, de modo que cada vez más son los ahorradores que deciden depositar su dinero por la misión social de la entidad. Así, en relación a los depósitos y plazo, sobresalen los depósitos a la vista, con total disponibilidad para los clientes, que se han incrementado en un $37,1 \%$ (véase Tabla 11). En 2016, el 62,7\% del total de los depósitos de clientes corresponde a los ahorros (incluye: cuentas de ahorro y depósitos a plazo fijo de particulares e instituciones sin ánimo de lucro) y el resto a otros fondos de clientes (incluye: cuentas corrientes de particulares e instituciones sin ánimo de lucro y todas las cuentas de Gobiernos, corporaciones no financieras y entidades financieras, excluidos los bancos).

Tabla. 11. Depósitos de clientes clasificados por plazo remanente, 2016-2014 (en miles de euros)*

\begin{tabular}{llll}
\hline & \multicolumn{1}{c}{$\mathbf{2 0 1 6}$} & \multicolumn{1}{c}{$\mathbf{2 0 1 5}$} & \multicolumn{1}{c}{$\mathbf{2 0 1 4}$} \\
\hline A la vista & 6.486 .533 & 5.621 .324 & 4.730 .659 \\
1 a 3 meses & 676.784 & 709.071 & 614.004 \\
3 meses a 1 año & 417.215 & 433.928 & 404.659 \\
1 a 5 años & 392.328 & 446.953 & 442.052 \\
Más de 5 años & 51.760 & 71.288 & 97.454 \\
\hline Total & $\mathbf{8 . 0 2 4 . 6 2 0}$ & $\mathbf{7 . 2 8 2 . 5 6 4}$ & $\mathbf{6 . 2 8 8 . 8 2 8}$ \\
\hline
\end{tabular}

(*) En el momento inicial se reconocen conforme a su valor razonable. Tras éste, se reconocen según el coste amortizado, esto es, el importe percibido teniendo en cuenta las primas o descuentos menos los costes de transacción. Por lo general, este importe se corresponde con su valor nominal.

Fuente: Triodos Bank. Informes Anuales, 2016-2014

Respecto al incremento de los Fondos Propios del Grupo, en este período se ha producido principalmente por un aumento de capital en Certificados de Depósitos para Acciones (CDA). Por otro lado, la prima de emisión de acciones está constituida por los desembolsos de capital por encima del valor nominal, descontando los impuestos de capital. La deuda subordinada se refiere a un 
préstamo en obligaciones a diez años con un interés nominal del 5,625\% y un precio de emisión de 99,314\%, emitido el 12 de julio de 2006.

En cuanto a la Cuenta de Pérdidas y Ganancias de la entidad, se observa que los ingresos se han incrementado un 14,8\% desde 2014, de modo que la actividad bancaria de Triodos crece progresivamente, respetando su misión y valores, y estableciendo unos intereses y comisiones acordes al proyecto financiado (véase Tabla 12).

Tabla. 12. Cuenta de Resultados consolidada, 2016-2014 (en miles de euros)

\begin{tabular}{|c|c|c|c|c|c|}
\hline & \multirow[b]{2}{*}{2016} & \multirow[b]{2}{*}{2015} & \multirow[b]{2}{*}{2014} & \multicolumn{2}{|c|}{ Variación $(\%)$} \\
\hline & & & & $16-15$ & $15-14$ \\
\hline Total Ingresos & 217.630 & 211.589 & 189.591 & $2,86 \%$ & $11,60 \%$ \\
\hline Intereses e ingresos asimilados & 174.557 & 182.752 & 173.654 & $-4,48 \%$ & $5,24 \%$ \\
\hline Intereses y cargas asimiladas & -32.435 & -39.855 & -47.404 & $18,62 \%$ & $15,92 \%$ \\
\hline Margen de intereses & 142.122 & 142.897 & 126.250 & $-0,54 \%$ & $13,19 \%$ \\
\hline $\begin{array}{l}\text { Ingresos de otras } \\
\text { participaciones }\end{array}$ & 179 & 101 & 109 & $77,23 \%$ & $-7,34 \%$ \\
\hline Ingresos por inversiones & 179 & 101 & 109 & $77,23 \%$ & $-7,34 \%$ \\
\hline Comisiones percibidas & 76.917 & 71.071 & 65.025 & $8,23 \%$ & $9,30 \%$ \\
\hline Comisiones pagadas & -3.510 & -3.396 & -2.841 & $-3,36 \%$ & $-19,54 \%$ \\
\hline Ingresos por comisiones & $\mathbf{7 3 . 4 0 7}$ & 67.675 & 62.184 & $8,47 \%$ & $\mathbf{8 , 8 3} \%$ \\
\hline $\begin{array}{l}\text { Resultados de operaciones } \\
\text { financieras }\end{array}$ & 404 & 774 & 551 & $-47,80 \%$ & $40,47 \%$ \\
\hline Otros ingresos & 1.518 & 142 & 497 & $969,01 \%$ & $-71,43 \%$ \\
\hline Otros ingresos & 1.922 & 916 & 1.048 & $109,83 \%$ & $-12,60 \%$ \\
\hline Total Gastos & 178.935 & 157.589 & 149.265 & $13,55 \%$ & $\mathbf{5 , 5 8} \%$ \\
\hline $\begin{array}{l}\text { Gastos de personal y otros } \\
\text { gastos de administración }\end{array}$ & 160.632 & 142.387 & 131.191 & $12,81 \%$ & $8,53 \%$ \\
\hline $\begin{array}{l}\text { Amortizaciones y ajustes de } \\
\text { valor de inmovilizado } \\
\text { inmaterial y material }\end{array}$ & 11.107 & 7.833 & 7.162 & $41,80 \%$ & $9,37 \%$ \\
\hline Costes de explotación & 171.739 & 150.220 & 138.353 & $14,32 \%$ & $\mathbf{8 , 5 8} \%$ \\
\hline $\begin{array}{l}\text { Ajustes por valoración de } \\
\text { activos }\end{array}$ & 5.711 & 7.579 & 11.093 & $-24,65 \%$ & $-31,68 \%$ \\
\hline $\begin{array}{l}\text { Ajustes por valoración de } \\
\text { participaciones en empresas }\end{array}$ & 1.485 & -210 & -181 & $-807,14 \%$ & $16,02 \%$ \\
\hline Resultado operativo antes de & 38.695 & 54.000 & 40.326 & $-28,34 \%$ & $33,91 \%$ \\
\hline
\end{tabular}




\section{impuestos}

\begin{tabular}{lrrrrr} 
Impuesto sobre el beneficio & -9.371 & -13.273 & -10.201 & $29,40 \%$ & $-30,11 \%$ \\
Beneficio neto & $\mathbf{2 9 . 3 2 4}$ & $\mathbf{4 0 . 7 2 7}$ & $\mathbf{3 0 . 1 2 5}$ & $\mathbf{- 2 8 , 0 0 \%}$ & $\mathbf{3 5 , 1 9 \%}$ \\
\hline
\end{tabular}

Fuente: Triodos Bank. Informes Anuales, 2016-2014

El mayor volumen de los ingresos procede de los intereses e ingresos asimilados derivados de la inversión crediticia y de las transacciones afines en el desarrollo de su actividad prestamista (préstamos, bancos, valores del Estado y otros valores representativos de deuda y otras inversiones), además de las comisiones percibidas.

Respecto a los gastos imputados a Triodos Bank, se observa que los gastos de personal (incluye la suma de salarios, gastos del plan de pensiones, gastos en seguridad y salud, empleados con contrato temporal, otros gastos de personal, menos los gastos de personal activados) y otros gastos de administración (incluye los gastos de: oficina, informática y tecnología, por administración externa, de viaje y estancia, de asesoramiento y auditoría, de marketing y comunicación, por arrendamientos y otros) se han incrementado un 19,9\% desde 2014, representando en 2016 el 89,9\% del total de gastos. Esta circunstancia se debe a la filosofía que se impone en el Grupo, puesto que dispone de una pequeña red de oficinas, de modo que la mayor parte de sus operaciones se realizan vía Internet o teléfono, requiriendo por tanto menos gasto en instalaciones. Reseñar que, aunque en 2015 se incrementó del Beneficio Neto respecto al ejercicio anterior en un 35,2\%, poniendo de manifiesto el buen funcionamiento de la actividad bancaria de Triodos, en 2016, ha disminuido un 28\%, debido al aumento de los costes de explotación, principalmente de los salarios (2016: 63.832; 2015: 58.580 miles de euros) y a los gastos de informática y tecnología (2016: 11.105; 2015: 7.916 miles de euros).

La actividad bancaria se mueve en un entorno de tipos de interés continuadamente bajos, de modo que este riesgo ha generado un descenso de los márgenes y, en consecuencia, una menor rentabilidad en comparación con las previsiones. La presión regulatoria lleva a contratar nuevo personal, y a adaptar los sistemas y procesos para aplicar los requisitos exigidos. Por otro lado, es necesario cuantificar el riesgo asumido por las entidades para intentar maximizar su rentabilidad financiera; quizá estén asumiendo riesgos excesivos que a medio y largo plazo pongan en peligro la solvencia y estabilidad del banco; de ahí la importancia de la gestión del riesgo.

Así, se analizan los riesgos asumidos por Triodos Bank en la concesión de créditos, es decir, qué parte del total son deudas de dudoso cobro (véase Tabla 13). 
Tabla. 13. Morosidad en los créditos concedidos (Grupo Triodos Bank y Triodos Bank España), 2016-2015 (en miles de euros)

\begin{tabular}{|c|c|c|c|c|c|c|c|c|}
\hline & \multicolumn{2}{|c|}{$\begin{array}{l}\text { Deudas de dudoso } \\
\text { cobro }\end{array}$} & \multicolumn{2}{|c|}{$\begin{array}{lr}\text { Provisión } & \text { por } \\
\text { deudas de } & \text { dudoso } \\
\text { cobro } & \end{array}$} & \multicolumn{2}{|c|}{$\begin{array}{l}\text { Correcciones } \\
\text { de valor }\end{array}$} & \multicolumn{2}{|c|}{$\begin{array}{l}\text { Deudas con } \\
\text { mora (excluidas } \\
\text { las deudas por } \\
\text { dudoso cobro) }\end{array}$} \\
\hline & 2016 & 2015 & 2016 & 2015 & 2016 & 2015 & 2016 & 2015 \\
\hline $\begin{array}{ll}\text { Triodos } & \text { Bank } \\
\text { España } & \end{array}$ & 39.577 & 47.724 & 9.772 & 8.515 & 3.019 & 2.459 & 12.026 & 12.920 \\
\hline $\begin{array}{l}\text { Grupo Triodos } \\
\text { Bank }\end{array}$ & 150.625 & 186.249 & 57.050 & 68.051 & 5.711 & 7.579 & 18.443 & 22.990 \\
\hline $\begin{array}{l}\text { Porcentaje } \\
\text { España/Grupo }\end{array}$ & $26,28 \%$ & $25,62 \%$ & $17,13 \%$ & $12,51 \%$ & $\begin{array}{l}52,86 \\
\%\end{array}$ & $\begin{array}{l}32,44 \\
\%\end{array}$ & $\begin{array}{l}65,21 \\
\%\end{array}$ & $\begin{array}{l}56,20 \\
\%\end{array}$ \\
\hline
\end{tabular}

Fuente: Triodos Bank. Informes Anuales, 2016-2015

En España, en 2016 el volumen total de créditos concedidos por Triodos Bank fue de 969.194 miles de euros, mientras que la entidad considera que aproximadamente 40 millones de euros son de dudoso cobro $(4,1 \%)$, por lo que anticipándose a esta situación, dota de provisiones y realiza las correspondientes correcciones. Respecto a las deudas con mora, con un retraso en el cobro de más de 90 días, de las que se excluyen las de dudoso cobro, Triodos únicamente tendría el $1 \%$ de sus créditos; y cae su tasa de morosidad por debajo de los niveles del mercado.

\subsection{Análisis comparativo con las principales entidades financieras españolas}

Para comprobar si las rentabilidades que obtiene Triodos Bank son significativas, el grado de apalancamiento y su nivel de solvencia, se realiza una comparación con otras entidades financieras tradicionales que, al igual que el banco ético, tienen una actividad bancaria internacional: Banco Santander y BBVA (véase Tabla 14). Como es sabido, son dos de las entidades más importantes a nivel mundial que cotizan en el IBEX 35, cuya red de oficinas está presente en multitud de países, con una actividad financiera consolidada.

\subsubsection{Análisis de rentabilidad}

La rentabilidad económica o de los activos (RoA) mide la eficiencia del comportamiento de las inversiones de la entidad, con independencia de cómo se hayan financiado. Así, en 2015 Triodos experimenta un pequeño aumento debido al incremento del Resultado operativo antes de impuestos, demostrando la capacidad del banco para vender sus productos en el mercado financiero; mientras 
que en 2016 vuelve a disminuir hasta el $0,30 \%$, por la menor diferencia entre ingresos y gastos respecto al ejercicio anterior.

Del mismo modo, la rentabilidad de los fondos propios (RoE) en 2016 disminuyó respecto al año anterior (2016: 3,5\%; 2015: 5,5\%). Triodos Bank señala que, a medio plazo su objetivo es incrementarla hasta el $7 \%$, aunque son conscientes de que con las exigentes condiciones de mercado esta rentabilidad deberá estar entre el 3\% y el 5\%, debido a los tipos de interés muy bajos, el aumento de los costes regulatorios y los requerimientos de capital y liquidez. Así, consideran que es preferible mantener un nivel de fondos propios alto, tener un exceso de tesorería, de modo que la RoE sea menor.

Tabla. 14. Rentabilidad económica y financiera (Triodos Bank, Banco Santander y BBVA), 2016-2014

\begin{tabular}{lllllll}
\hline & \multicolumn{2}{c}{2016} & \multicolumn{2}{c}{2015} & \multicolumn{2}{c}{2014} \\
\hline \multirow{2}{*}{ Triodos Bank } & RoE & RoA & RoE & RoA & RoE & RoA \\
\cline { 2 - 7 } Banco Santander & $3,50 \%$ & $0,30 \%$ & $5,50 \%$ & $0,50 \%$ & $4,40 \%$ & $0,40 \%$ \\
BBVA & $6,99 \%$ & $0,56 \%$ & $6,57 \%$ & $0,54 \%$ & $7,05 \%$ & $0,58 \%$ \\
\hline
\end{tabular}

Fuente: Informes Anuales, 2016-2014

La comparativa de Banco Santander y BBVA con Triodos muestra que la diferencia entre las rentabilidades no es acusada. La rentabilidad económica de las tres entidades se encuentra en el intervalo del 0,30\% y $0,65 \%$, siendo relativamente pequeña debido a la limitada capacidad del sector financiero para generar valor de sus activos. Por otro lado, Triodos, con una tendencia decreciente, en 2016 presenta una rentabilidad financiera inferior al modelo tradicional, de modo que Triodos está generando menos valor a sus accionistas, debido a la elevada competitividad y la restricción impuesta en sus inversiones.

Asimismo, en general se observa que las diferencias entre las tasas de rentabilidad no son significativas entre las entidades, considerando así que el cliente de banca ética cada vez más tiene la certeza de que su dinero promueve proyectos que aportan un beneficio social.

En el sector bancario la responsabilidad social corporativa tiene especial importancia, porque se distingue una doble vía (De la Cuesta, Muñoz y Fernández, 2006): por un lado, iniciativas de responsabilidad ambiental (mejora del rendimiento energético, prácticas de reciclaje de residuos, etc.) y social (políticas de mejora en recursos humanos, donaciones caritativas, patrocinio de actividades culturales y asistenciales, etc.) en la gestión interna del banco, de forma similar a lo que podrían hacer otras empresas del sector no financiero; por otro lado, y lo que constituye una particularidad de este sector, a nivel externo la banca tiene un alto impacto en responsabilidad social y sostenibilidad a través de la incorporación de prácticas en este sentido dentro del negocio de intermediación bancaria y de inversión en los mercados financieros (productos de ahorro socialmente responsables, como fondos de pensiones, fondos de inversión o depósitos éticos, 
créditos a proyectos que consideran el impacto social y medioambiental, etc.). La banca tradicional se ha centrado tradicionalmente en promocionar la dimensión interna, mientras que la dimensión externa es sólo considerada en sentido amplio por la denominada banca ética, como es el caso de Triodos Bank.

Como consecuencia de esta implicación, Triodos Bank es una B Corporation, calificada como tal por el B Lab al cumplir rigurosos estándares de responsabilidad social y medioambiental, así como de transparencia. De hecho, en 2015 el B Score de Triodos fue 127, mientras que la media de las compañías calificadas como B Corps es de 55 (actualmente hay más de 2.100 compañías certificadas como B Corps, pertenecientes a 50 países), y entre las mismas no se encuentran ni Banco Santander ni BBVA. Ahora bien, eso no significa que estas últimas entidades bancarias sean ajenas a las prácticas de responsabilidad social corporativa, pues ambas presentan informes en el GRI, desde 2003 Banco Santander y desde 2004 BBVA; sin embargo, Triodos ya los presentaba desde el año 2000.

En suma, habría que considerar que la inferior rentabilidad en términos monetarios de Triodos habría que contemplarla junto a una mayor performance social. En este sentido, no obstante, hay estudios que demuestran la correlación positiva entre la rentabilidad económica o financiera y la rentabilidad social, aconsejando a las empresas financieras incorporar políticas de responsabilidad social, especialmente en la dimensión referida a empleados, gobierno corporativo y relaciones con la comunidad (Esteban, De la Cuesta y Paredes, 2017).

\subsubsection{Apalancamiento}

Los niveles de rentabilidad financiera también se ven afectados por el nivel de apalancamiento de las entidades, definido como el cociente entre el capital regulatorio requerido de Nivel 1, o CET1, y el total de activos bancarios, incluidos los que están fuera de balance. Así, con el ratio de apalancamiento se limita el exceso de deuda que una entidad pueda asumir, además de contar con una medida complementaria que refuerza los requerimientos de capital independientemente del riesgo.

La banca tradicional, Banco Santander y BBVA, capta el capital principalmente a través de sus acciones en Bolsa, asumiendo mayores riesgos y disponiendo de un importe menor de fondos propios, por lo que su nivel de apalancamiento es menor, afectando de manera positiva a su rentabilidad financiera. Triodos Bank, en cambio, al no ser una entidad cotizada, capta el capital de los depósitos de sus clientes, y así apuestan por reforzar su capital y evitar asumir los riesgos inherentes al mercado bursátil (véase Figura 3). 
Figura. 3. Ratio de Apalancamiento* (Triodos Bank, Banco Santander y BBVA), 20162014

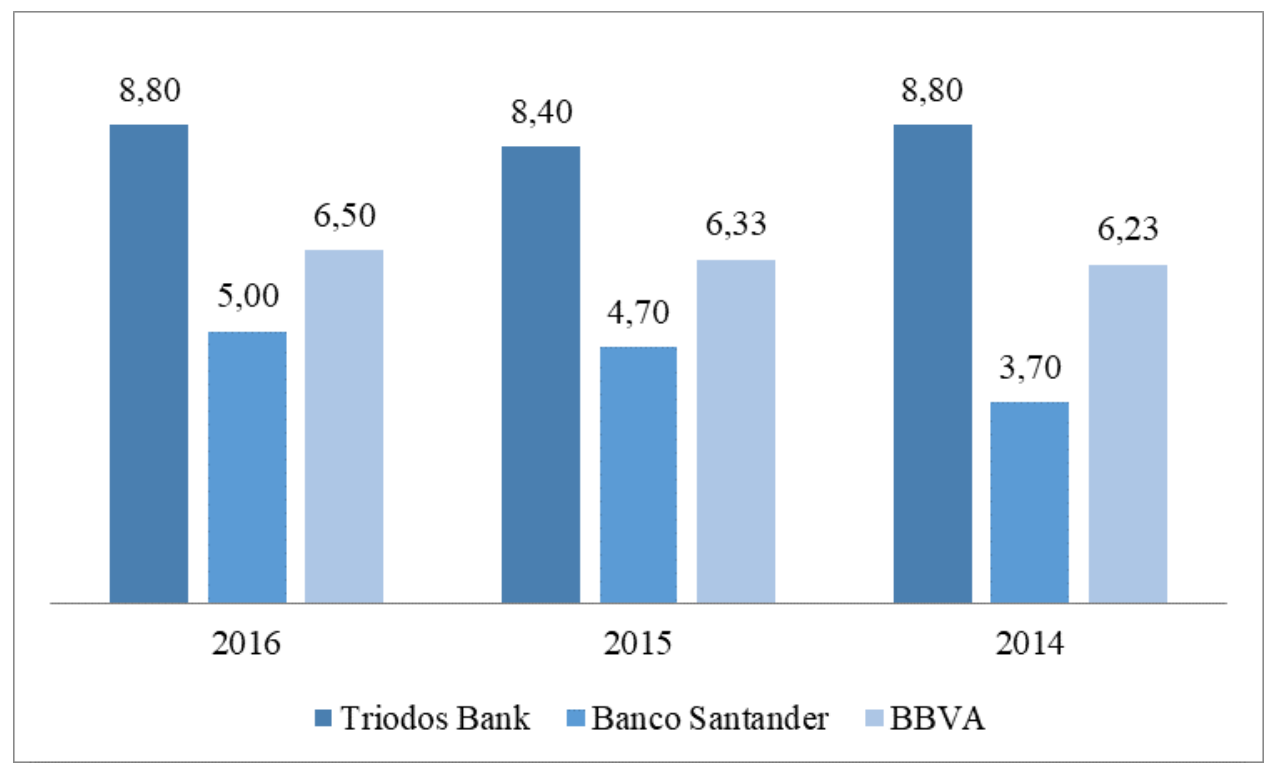

(*) Calculado según las normas financieras establecidas en:

. Directiva 2013/36/UE del Parlamento Europeo y del Consejo, de 26 de junio de 2013, relativa al acceso a la actividad de las entidades de crédito y a la supervisión prudencial de las entidades de crédito y las empresas de inversión, por la que se modifica la Directiva 2002/87/CE y se derogan las Directivas 2006/48/CE y 2006/49/CE.

. Reglamento (UE) N o 575/2013 del Parlamento Europeo y del Consejo, de 26 de junio de 2013, sobre los requisitos prudenciales de las entidades de crédito y las empresas de inversión, y por el que se modifica el Reglamento (UE) n o 648/2012.

. Véase: Marco del coeficiente de apalancamiento de Basilea III y sus requisitos de divulgación, enero de 2014, www.bis.org/publ/bcbs270_es.pdf.

Fuente: Elaboración propia. Informes Anuales, 2016-2014

\subsubsection{Análisis de solvencia}

La Tabla 15 muestra los datos que informan de la solvencia de Triodos Bank, Banco de Santander y BBVA, en el período de 2014 a 2016. Respecto a la cobertura de liquidez, que indica la capacidad del banco para mantener un nivel de activos fácilmente convertibles en líquidos con los que afrontar sus obligaciones financieras ante una situación de inestabilidad, se observa que Triodos tiene mayor facilidad que Banco Santander y BBVA para hacer líquidos sus activos.

La ratio de Financiación Neta Estable (NSFR, por sus siglas en inglés) se establece como el cociente entre la cantidad de financiación estable disponible (ASF, proporción entre recursos propios y ajenos que cabe esperar serán fiables en el horizonte temporal considerado) y la cantidad de financiación estable requerida (RSF, la requerida por una institución concreta en función de las características de liquidez y vencimiento de los activos), que deberá ser del 100\% como mínimo 
permanentemente. Triodos está en línea con las entidades tradicionales Y ofrece un perfil de financiación estable en relación con la composición de sus activos y actividades fuera de balance, de modo que ha reducido la probabilidad de que la perturbación de sus fuentes de financiación deteriore su posición de liquidez de forma que aumente su riesgo de quiebra.

En este contexto, en el marco regulatorio (Basilea III) para fortalecer el sistema bancario, impulsado por el Comité de Supervisión Bancaria de Basilea y su órgano de vigilancia, el Grupo de Gobernadores y Jefes de Supervisión (GHOS), se acuerdan medidas para mejorar la calidad del capital regulatorio, la coherencia a escala internacional y su transparencia, encaminadas a asegurar que el sistema esté en mejores condiciones para absorber las pérdidas, tanto si las entidades siguen en funcionamiento para garantizar su viabilidad (capital de nivel 1 o Tier 1) como si dejaran de ser viables (capital de nivel 2 o Tier 2). Así, el Tier 1 está formado por el capital de mayor calidad o Common Equity y por los elementos adicionales de Tier 1 (instrumentos híbridos). En este sentido, la ratio de Capital Tier 1 expresa el porcentaje de exposición al riesgo que tienen las entidades, y es útil para determinar la solvencia de la entidad. Triodos tiene capital para hacer frente a imprevistos, sobre todo, tras las emisiones de CDA.

Tabla. 15. Análisis de Solvencia (Triodos Bank, Banco Santander y BBVA), 2016-2014

\begin{tabular}{|c|c|c|c|c|c|c|c|c|c|}
\hline & \multicolumn{3}{|c|}{ Triodos Bank } & \multicolumn{3}{|c|}{ Banco Santander } & \multicolumn{2}{|c|}{ BBVA } & \multirow[b]{2}{*}{2014} \\
\hline & 2016 & 2015 & 2014 & 2016 & 2015 & 2014 & 2016 & 2015 & \\
\hline $\begin{array}{l}\text { Cobertura de } \\
\text { Liquidez }^{1}\end{array}$ & $319 \%$ & $451 \%$ & $642 \%$ & $\begin{array}{l}146 \\
\%\end{array}$ & $146 \%$ & $120 \%$ & $74 \%$ & $70 \%$ & $64 \%$ \\
\hline $\begin{array}{l}\text { Financiación Neta } \\
\text { Estable }^{2}\end{array}$ & $159 \%$ & $158 \%$ & $165 \%$ & n.d. ${ }^{4}$ & n.d. & n.d. & n.d. & n.d. & n.d. \\
\hline Capital Tier $1^{3}$ & $\begin{array}{l}19,20 \\
\%\end{array}$ & $\begin{array}{l}19,01 \\
\%\end{array}$ & $19 \%$ & $\begin{array}{l}11,53 \\
\%\end{array}$ & $11 \%$ & $\begin{array}{l}10,46 \\
\%\end{array}$ & $\begin{array}{l}12,9 \\
0 \%\end{array}$ & $\begin{array}{l}12,1 \\
0 \%\end{array}$ & $\begin{array}{l}11,90 \\
\%\end{array}$ \\
\hline
\end{tabular}

Notas:

${ }^{1}$ Véase Basilea III: Coeficiente de cobertura de liquidez y herramientas de seguimiento del riesgo de liquidez, enero de 2013, www.bis.org/publ/bcbs238_es.pdf

2 Véase Basilea III: Coeficiente de Financiación Estable Neta, octubre de 2014, www.bis.org/bcbs/publ/d295_es.pdf.

${ }^{3}$ El ratio de capital Tier 1 (común) se ha calculado según las normas de información financiera establecidas en la Directiva sobre Requerimientos de Capital (CRD) y el Reglamento sobre Requerimientos de Capital (CRR).

${ }^{4}$ n.d. $=$ no declarado

Fuente: Informes Anuales, 2016-2014

En general, Triodos tiene una posición tan solvente como las entidades BBVA y Banco Santander, a pesar de los mayores riesgos que éstas asumen para obtener una mayor rentabilidad. Así, destaca que Triodos Bank, considerando las duras medidas de capital y liquidez impuestas por la regulación bancaria, se encuentra en una situación de fortalecimiento financiero, con una alta solvencia, capitalizada 
fuertemente y que dispone de liquidez suficiente para hacer frente a los posibles imprevistos que surjan en los mercados. Además, sus cifras han demostrado que se encuentra en una fase importante de crecimiento, con un incremento anual de sus depósitos y créditos, que la ubica en una posición privilegiada en el sector de la banca ética en Europa, y en España, donde su implantación está resultando un éxito.

\section{Conclusiones}

Las finanzas éticas, que empezaron a desarrollarse en los años 60, han tenido un creciente interés a partir de la última crisis económica mundial que, como han expresado muchas voces, ha venido provocada realmente por una crisis de valores. En este sentido, el modelo de negocio de Triodos Bank se centra en la financiación de proyectos de inversión comprometidos con la mejora y el cuidado de la naturaleza y el medioambiente, destinando a ello casi un 50\% del total de préstamos concedidos; el desarrollo de sectores sociales más desfavorecidos y la promoción de la cultura con fines y valores éticos, con alrededor de un $40 \%$ de sus inversiones; mientras que, poco más del $10 \%$ es dedicado a créditos a particulares $\mathrm{y}$, en menor medida, a ayuntamientos. No obstante, estos préstamos a particulares se incrementan paulatinamente, con la finalidad de cubrir las necesidades de aquellos grupos sociales excluidos de la banca tradicional.

El número de clientes de banca ética ha aumentado en España un $48 \%$ entre 2013 y 2016. En lo que respecta a Triodos Bank, en tan solo 2 años, entre 2014 y 2016, ha aumentado su Balance de situación en más de un 25\%, debido tanto al crecimiento de depósitos como a ampliación de su capital. Un 63\% de su Activo es la inversión crediticia, la mayor parte a largo plazo, pero hay que señalar el aumento de los préstamos a 1 y 3 meses en forma de microcréditos para la puesta en marcha de pequeños negocios. A diferencia de la banca tradicional, la mayor parte de los préstamos concedidos son financiados con los depósitos de clientes y no con préstamos recibidos de otras entidades. De hecho, en estos 2 años, los depósitos han aumentado más de un $27 \%$, lo que muestra la confianza de los ahorradores en la entidad y su buena reputación.

La rentabilidad económica de Triodos Bank está por debajo del 1\%, pero en línea con las grandes entidades bancarias tradicionales Santander y BBVA. Sin embargo, la rentabilidad financiera es sensiblemente inferior, especialmente en 2016, donde Triodos está en un 3,5\%, mientras que la banca tradicional se sitúa en casi un 7\%; ello es debido a la distinta filosofía a la hora de financiarse, puesto que Triodos tiene una mayor proporción de recursos propios, lo que le supone una mejor solvencia.

La elevada capitalización de Triodos, unido a su buena solvencia y liquidez, así como la fase de crecimiento en la que se encuentra, muestra cómo se está implantando con éxito, tanto en España como en Europa, y es garantía de un futuro prometedor. Podemos decir que la banca ética está en alza. 


\section{Referencias bibliográficas}

Alejos Góngora, C. L. (2014) Banca ética: una alternativa viable. IESE Business School. Universidad de Navarra. Cuadernos de la Cátedra "la Caixa" de Responsabilidad Social de la Empresa y Gobierno Corporativo, № 23.

Alemán Alonso, J. J. (2015) El crecimiento de la banca ética en España frente al descrédito de la banca tradicional. Actas I Congreso internacional de la Red española de Filosofía, Vol. XV, pp. 67-78.

Banco de España (2017) Informe sobre la crisis financiera y bancaria en España, 20082014.

Baraibar-Diez, E.; Odriozola, M. D. y Fernández Sánchez, J. L. (2017) Communication transparency in ethical and traditional banking in Spain. Journal of International Business Research and Marketing, $\mathrm{N}^{\circ}$ 2, Vol. 2, pp. 24-32. DOI: http://dx.doi.org/10.18775/jibrm.1849-8558.2015.22.3004.

Bosheim, S. A. (2012) Social banks and impact measurement: The cases of Charity Bank and Triodos Bank. ISB Paper Series, $\mathrm{N}^{\circ} 10$.

Cabaleiro Casal, M. J. y Rodríguez Parada, S. M. (2008) Sociedades cooperativas de banca alternativa. REVESCO. Revista de Estudios Cooperativos, Segundo Cuatrimestre, $\mathrm{N}^{\circ}$ 95, pp. 44-64.

Castro Cotón, M. y Romero Castro, N. (2011) Cooperativas de crédito y banca ética: ¿Un camino por explorar? Ciriec-España. Revista de Economía Pública, Social y Cooperativa, $\mathrm{N}^{\mathrm{0}}$ 72, pp. 263-300.

Chew, B. C.; Tan, L. H. y Hamid, S. R. (2016) Ethical banking in practice: a closer look at the Co-operative Bank UK PLC. Qualitative Research in Financial Markets, $\mathrm{N}^{\circ}$ 8, Vol. 1, pp. 70-91.

Condosta, L. (2012) How banks are supporting local economies facing the current financial crisis: An Italian perspective. International Journal of Bank Marketing, $\mathrm{N}^{\circ} 30$, Vol. 6, pp. 485-502.

Cornée, S. (2017) The relevance of soft information for predicting small business credit default: Evidence from a social bank. Journal of Small Business Management. doi.org/10.1111/jsbm.12318

Cowton, C. J. y Thompson, P. (2001) Financing the social economy: a case study of Triodos Bank. International Journal of Nonprofit and Voluntary Sector Marketing, $\mathrm{N}^{\circ}$ 6, Vol. 2, pp. 145-155.

De la Cruz Ayuso, C. y Sasia Santos, P. M. (2010) La banca ética como herramienta de acción política. Icade: Revista de las Facultades de Derecho y Ciencias Económicas y Empresariales, $\mathrm{N}^{\circ}$ 80, pp. 185-210.

De la Cruz Ayuso, C.; Sasia Santos, P. M. y Garibi, J. (2006) Lo que debe ser y es una a banca ética. Lan harremanak: Revista de relaciones laborales, $\mathrm{N}^{\circ} 14$, pp. 175-204.

De la Cuesta González, M.; Muñoz Torres, M.J. y Fernández Izquierdo, M. A. (2006) Analysis of social performance in the Spanish financial industry through public data. A proposal. Journal of Business Ethics, Vol. 69, pp.289-304.

De la Orden de la Cruz, C. y Sánchez González, P. (2016) Desarrollos de banca ética y viabilidad de la banca islámica. Opción, $\mathrm{N}^{\circ} 32$, Vol. 9.

Dorasamy, N. (2013) Corporate Social Responsibility and Ethical Banking for Developing Economies. Journal of Economics and Behavioral Studies, $\mathrm{N}^{\circ}$ 11, Vol. 5, pp. 777-785.

Esteban Sánchez, P.; De la Cuesta González, M. y Paredes Gázquez, J.D. (2017) Corporate social performance and its relation with corporate financial perfomance: international 
evidence in the banking industry. Journal of Cleaner Production, Vol. 162, pp. 11021110.

Gassiot Ballbè, R. (2013) Las finanzas éticas como instrumento al servicio de la economía solidaria. La experiencia de Coop57. Cuadernos de Trabajo Social, Vol. 26-1, pp. 7584. DOI: http://dx.doi.org/10.5209/rev_CUTS.2013.v26.n1.40596.

GLOBAL ALLIANCE FOR BANKING ON VALUES (GABV) (2016) Economía RealGanancias Reales: Un caso de negocio continuo para la banca centrada en la sostenibilidad. Informe de Investigación de 2016.

GLOBAL ALLIANCE FOR BANKING ON VALUES (GABV) (2017) Members.

Gutiérrez Nieto, B. (2004) Hacia una clasificación de los productos de financiación social en España: consolidación del microcrédito y primeros pasos de la creación de un banco ético. Boletín de estudios económicos, $\mathrm{N}^{\circ} 182$, Vol. 59, pp. 323-342.

Halamka, R. y Teplý, P. (2017) The Effect of Ethics on Banks' Financial Performance. Prague Economic Papers, No 3, pp. 330-344.

Karl, M. (2015) Are Ethical and Social Banks Less Risky? Evidence from a New Dataset, Discussion Papers of DIW Berlin, DIW Berlin, German Institute for Economic Research, № 1484 .

Knights, D. (2009). The failure of regulation in banking: ethical reflections. In 13th European Business Ethics Network UK Conference, Bristol, pp. 6-8.

Kousis, M. (2017). Alternative Forms of Resilience Confronting Hard Economic Times. A South European Perspective. Partecipazione e conflitto, № 10, Vol. 1, pp. 119-135.

Mishra, D. K. (2015) Green Banking: Comparing Environmental Sustainability with Socially Responsible Investments. International Journal of Biological Sciences and Engineering, $\mathrm{N}^{\circ}$ 1, Vol. 6, pp. 24-30.

Narrillos Roux, H. (2010) El SROI (social return on investment): un método para medir el impacto social de las inversiones. Análisis financiero, No 113 , pp. 34-43.

Ochoa Berganza, J. (2013) Finanzas para una economía humana sostenible: hacia la banca ética. Revista de dirección y administración de empresas=Enpresen zuzendaritza eta administraziorako aldizkaria, $\mathrm{N}^{\mathrm{o}}$ 20, pp. 123-143.

Paulet, E.; Parnaudeau, M. y Relano, F. (2015) Banking with ethics: Strategic moves and structural changes of the banking industry in the aftermath of the subprime mortgage crisis. Journal of Business Ethics, No 131, Vol. 1, pp. 199-207.

Pérez-Ruiz, A. y Rodríguez del Bosque, I. (2012) La imagen de Responsabilidad Social Corporativa en un contexto de crisis económica: el caso del sector financiero en España. Universia Business Review, Primer Trimestre, № 33, pp. 14-29.

Retolaza Ávalos, J. L. y San Emeterio, J. (2003) ¿Existe espacio para una banca ética? Lan harremanak: Revista de relaciones laborales, $\mathrm{N}^{\mathrm{o}}$ 9, pp. 127-163.

Rosero Villabón, O. G.; Pinzón, J. V. y Ramírez, G. A. (2013) Responsabilidad Social Corporativa En La Banca Europea: Un Estudio Empírico Comparativo Entre Organizaciones De 15 Países. Sotavento MBA, No 22.

Ruiz Sánchez, B.; Esteban Talaya, A. y Gutiérrez Broncano, S. (2014) Reputación bancaria durante la crisis económica. Comparación entre las principales entidades financieras desde la perspectiva del cliente. Universia Business Review, Tercer trimestre, № 43, pp. 16-35.

San José Ruiz de Aguirre, L. y Retolaza Ávalos, J. L. (2007) Análisis comparativo de la banca ética con la banca tradicional: identificación de indicadores. Conocimiento, innovación y emprendedores: Camino al futuro (coord. por Juan Carlos Ayala Calvo). Universidad de La Rioja. 
San José Ruiz de Aguirre, L.; Retolaza Ávalos, J. L. y Gutiérrez Goiria, J. (2011) Are Ethical Banks Different? A Comparative Analysis Using the Radical Affinity Index. Journal of Business Ethics, N 1, Vol. 100, pp. 151-173.

San José Ruiz de Aguirre, L.; Retolaza Ávalos, J. L. y Pruñonosae, J. T. (2014) Efficiency in Spanish banking: A multistakeholder approach analysis. Journal of International Financial Markets, Institutions \& Money, № 32. pp. 240-255.

Sanchís Palacio, J. R. (2016) La revolución de las finanzas éticas y solidarias. La economía social y solidaria: experiencias y retos. Oikonomics. Revista de Economía, Empresa y Sociedad, No 6, pp. 28-34.

Sanchís Palacio, J. R. y Pascual García, E. (2017) Banca ética y banca cooperativa. Un análisis comparativo a través del estudio de Caixa Popular y de Fiare Banca Ética. REVESCO. Revista de Estudios Cooperativos, Segundo Cuatrimestre, $\mathrm{n}^{\circ} 124,1$. DOI: 10.5209/REVE.54921.

Sasia Santos, P. M. (2012) La Banca Ética en Europa: el enfoque del crédito como criterio de configuración de un espacio de alternativa. Ciriec-España. Revista de Economía Pública, Social y Cooperativa, No 75, pp. 276-299.

Serrano Pérez, M. E. (2017) El índice SEBI como medida del nivel de compromiso con los principios que definen la banca ética. Contaduría y Administración. DOI: http://dx.doi.org/10.1016/j.cya.2017.06.001.

Soler Tormo, F. y Melián Navarro, A. (2012) Cooperativas de crédito y banca social: viejas y nuevas respuestas éticas y solidarias a problemas de siempre. REVESCO. Revista de Estudios Cooperativos, Tercer Cuatrimestre, $\mathrm{N}^{\mathrm{o}} 109$, pp. 45-80. DOI: 10.5209/rev_REVE.2012.v109.40655.

Toke, D. (2005) Community wind power in Europe and in the UK. Wind Engineering, $\mathbf{N}^{\mathrm{o}}$ 29, Vol. 3, pp. 301-308.

Toña Guenaga, A.; Sasia, P. y Garibi, J. (2006) Posibilidades de estructuración de una banca ética en España. Documentación Social, No 142, pp. 157-174.

Vidal, P.; De la Peña Rodríguez, M.; Zaragoza, M. y Sureda, M. (2006) Diagnóstico sobre el interés del tercer sector y la economía social por una banca ética. FETSFinanciación Ética y Solidaria. Observatorio del Tercer Sector, Barcelona. 